\title{
RISCO E VULNERABILIDADE AMBIENTAL URBANA NA REGIÃO METROPOLITANA DE MANAUS
}

\author{
Rayane Brito de Almeida \\ Mestranda do Programa de Pós-graduação em Geografia - UFAM \\ Universidade Federal do Amazonas \\ rayanebritodealmeida@gmail.com
}

\begin{abstract}
RESUMO: Este estudo objetivou identificar e analisar a relação entre a interação entre a dinâmica da pluviosidade e temperatura com os casos confirmados de dengue e malária nas cidades de Manaus e Itacoatiara e as estruturas de risco e vulnerabilidade. O texto foi fundamentado segundo o Sistema Ambiental Urbano (S.A.U.). Alguns resultados identificaram que as condições climáticas favoráveis ao ciclo do vetor Anopheles são chuvas entre 40 e $110 \mathrm{~mm}$, temperatura do ar entre 24 a $32{ }^{\circ} \mathrm{C}$ e a periodicidade dos casos de malária ocorrem com maior intensidade nos meses do período de estiagem (junho a outubro) e menor intensidade nos meses mais chuvosos (março a maio). As condições favoráveis ao Aedes aegypti consistem em chuvas entre 10 a $20 \mathrm{~mm}$ e temperatura entre 27 a $30^{\circ} \mathrm{C}$. A formação de ambientes ecológicos para estes vetores são potencializados por problemas de injustiça e desigualdade sócioespaciais, o que causa a expansão e intensificação dos casos de malária e dengue, principalmente por problemas de saneamento, como o acumulo inadequado de lixo.
\end{abstract}

Palavras-chave: sistema ambiental urbano, ambiente ecológico, doenças.

\section{INTRODUÇÃO}

A pesquisa tem como objetivo analisar a relação entre doenças e a dinâmica climática no contexto social, político, econômico e ambiental da Região Metropolitana de Manaus, em particular, as doenças leptospirose, malária, dengue, zika, chikungunya, hepatite, febre tifoide e diarreia. Estas doenças têm em sua etiologia patológica, condicionantes socioambientais, como a própria influência das chuvas e temperatura no desenvolvimento dos vetores Aedes aegypti e o Anopheles, em seu ciclo larval, como a precariedade de serviços públicos e equipamentos urbanos, especialmente nas áreas periféricas que são estruturadas em condições de pobreza, que segundo Grazia e Queiroz (2001, p.91) a condição de pobreza de uma dada população está "estreitamente relacionada à condição de formação de riscos e de vulnerabilidade socioambiental".

No primeiro momento, o presente texto abordou apenas a situação epidemiológica da dengue e malária nas cidades de Manaus e Itacoatiara nos últimos cinco anos, as demais doenças estão em fase de elaboração e análise. Deste modo, o objetivo foi analisar a interação entre a dinâmica da pluviosidade e temperatura com os casos confirmados de dengue e malária nas cidades de Manaus e Itacoatiara, identificando também os condicionantes socioeconômicos que potencializam a intensa e contínua frequência de sujeitos afetados por estas doenças, isto é, como reprodução de estruturas de risco e vulnerabilidade. 


\section{MATERIAIS E MÉTODOS}

A análise parte da abordagem socioambiental, por meio do Sistema Ambiental Urbano de Mendonça $(2004,2009)$, uma metodologia para o estudo integrado da cidade a partir da relação sociedade e natureza, como a formação de ambientes ecológicos aos vetores Aedes aegypti e o Anopheles, tanto estes vetores como o vírus da dengue e da malária, plasmodium, são a princípio elementos da natureza, são vetores e vírus desenvolvidos em particularidades tropicais.

Todavia, "a desigualdade socioeconômica estruturada no espaço cria fragilidades ambientais urbanas que propiciam ambientes potenciais à produção do risco de malária" (ALMEIDA \& COSTA, 2017, p.12758). O desmatamento e construção de novas moradias muitas vezes não são feitos com infraestrutura adequada e acarretam em áreas de risco e vulneráveis, contribuindo para a formação de criadouros de vetores (ALMEIDA \& COSTA, 2017; GUALBERTO \& GONÇALVES, 2015).

\section{RESULTADOS E DISCUSSÃO}

A situação de malária em Itacoatiara, os casos se intensificaram a partir de 2016, havendo uma epidemia no ano de 2017 (Gráfico 01), totalizando 3.165 casos confirmados de malária, onde grande parte dos casos se concentrou nas comunidades rurais (FVS, 2018).

Gráfico 01 - relação entre clima e malária em Itacoatiara. Org: Autora.

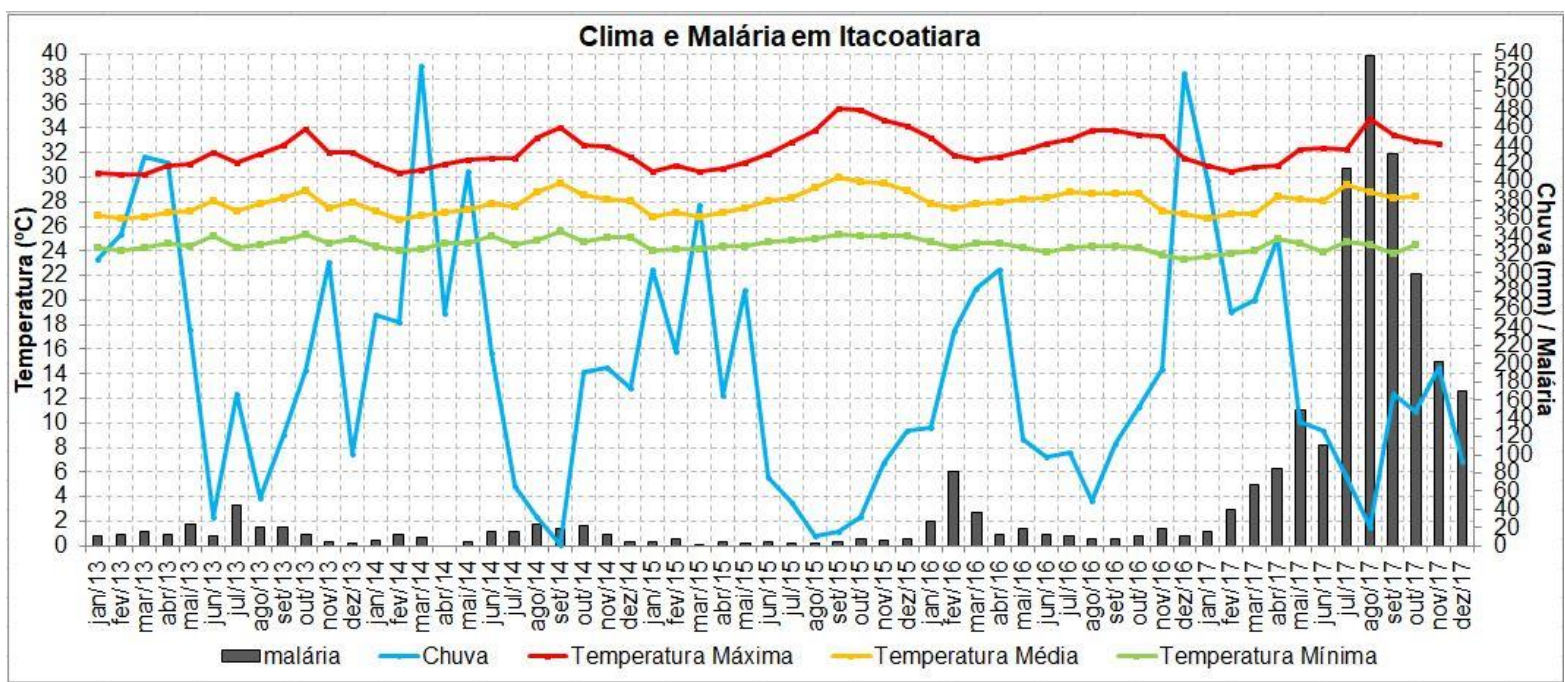

Conforme a Gráfico 01, os casos de malária predominam nos meses de estiagem, junho a agosto, entre 20 a 60 casos nos anos de 2013 a 2016, em 2017, os casos se mantiveram elevados, com picos de 420 a 540 casos no período de estiagem. A condição climática favorável ao ciclo do vetor anopheles variou entre 24 e $32^{\circ} \mathrm{C}$, com 
chuvas entre 40 e $110 \mathrm{~mm}$. Somando a isto, há também a formação de criadouros por materiais gárbicos que são descartados inadequadamente a céu aberto, apontado pela secretaria de saúde da cidade como o maior problema de saneamento na cidade e potencializador tanto da malária como da dengue. Este problema forma encontrados em quintais, ruas e nas margens de igarapés urbanos, intensificando ainda mais a formação de ambiente ecológico do anopheles, que segundo Gonçalvez \& Alecrim (2004) são potenciais ao desenvolvimento de epidemias de malária.

Há também um grande predomínio de vegetação em torno das habitações, o que é característico em todos os bairros, retendo a umidade e servindo como abrigo natural aos anopheles, para Tadei (1993) e Terraza (2005), também é apontado como "fator ambiental favorável à transmissão".

Em relação aos casos confirmados de dengue (Gráfico 02 ), estes predominam com maior intensidade durante o período chuvoso, em particular nos meses fevereiro e março, foram registrados entre 900 a 1.400 casos confirmados. As condições de chuvas favoráveis variam entre 10 a $20 \mathrm{~mm}$ e temperatura entre 27 a $30^{\circ} \mathrm{C}$.

Gráfico 02 - relação entre clima e dengue em Manaus. Org: Autora.

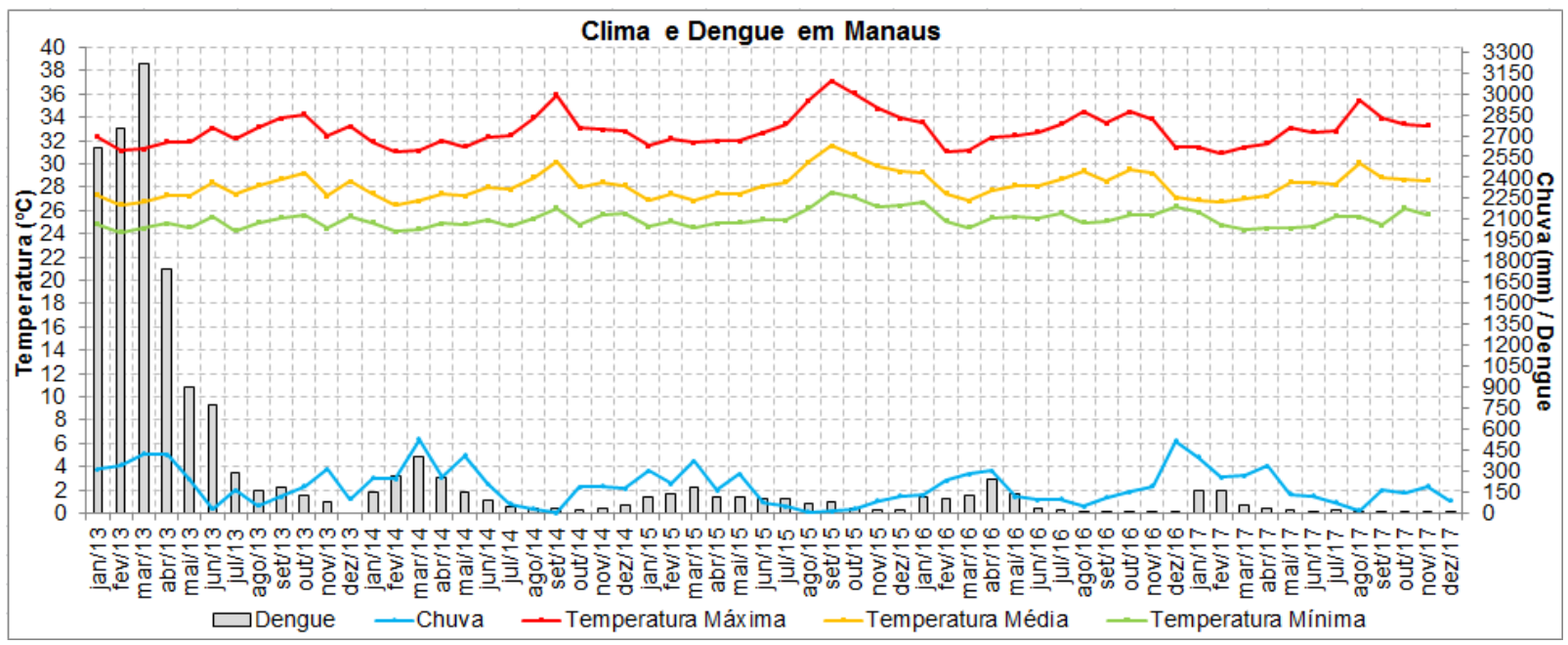

Durante o período de estiagem também houve casos confirmados da doença, mas com menor intensidade, foram registrados entre 200 e 400. Nesta série histórica apresentada só foi identificada uma epidemia, no ano de 2013, segundo Castro e Costa (2017), foi a última epidemia registrada em Manaus, ou seja, casos notificados acima de 10.000, os demais anos são considerados apenas como surtos, situação de alerta.

O ambiente ecológico do Anopheles e Aedes aegypti tem como condicionantes socioambientais, a precariedade de saneamento nas cidades de Manaus e Itacoatiara e condições climáticas favoráveis à reprodução dos vetores, assim corroborou Mendonça et. al (2009) quando aborda os diversos fatores que potencializaram para a recorrência de formação de epidemias de dengue nos países tropicais e subtropicais, ele destaca o acelerado crescimento demográfico associado à "intensa 
desordenada urbanização, a inadequada infraestrutura urbana, o aumento da produção de resíduos não-orgânicos, os modos de vida na cidade, a debilidade de serviços e campanhas de saúde pública, até mesmo o despreparo de agentes da saúde e da própria população para o controle da doença (p. 258)". O que é característico em ambas as cidades aqui abordadas.

\section{REFERÊNCIAS}

ALMEIDA, R. B. ; COSTA, R. C. Incidência de malária: clima e sistema ambiental urbano (S.A.U.) em Manaus, AM. Disponível em: http://www.enanpege.ggf.br/2017/anais/arquivos/GT\%2043/1153.pdf. Acessado em 07 de mar. 2018.

CASTRO, M.B.; COSTA, R. C. 2017. Clima urbano e a dengue em Manaus-AM. In: COSTA, R.C., Riscos, fragilidades \& problemas ambientais urbanos em Manaus. Ed. INPA, Manaus, 2017. p. 31-57.

FUNDAÇÃO DE VIGILÂNCIA EM SAÚDE. Resumo Epidemiológico para a malária. FVS de Itacoatiara. SIVEP-MALÁRIA. 2017.

GRAZIA, G.; QUEIROZ, L.L. et. al. O desafio da sustentabilidade urbana. Rio de Janeiro: FASE/IBASE, Série Cadernos Temáticos, n.5, 2001.

GONÇALVEZ, m. j. \& ALECRIM, W. D. Non-planed urbanization as a contribuiting fator for malária incidence in Manaus-Amazonas, Brasil. Revista de Saúde Pública. v.6, n.2, p. 156-166, 2004.

GUALBERTO, A. K. M.; GONÇALVES, M. J. F. Aspectos epidemiológicos e ambientais da malária em Manaus, 1998-2010. In: FREITAS, C. M. \& GIATTI, L. L. (Org.). Sustentabilidade, Ambiente e Saúde na cidade de Manaus. Manaus: Edua e Editora Fiocruz, p.183-192, 2015.

MENDONÇA, F. S.A.U. - Sistema Ambiental Urbano: Uma abordagem dos problemas socioambientais da cidade. In: MENDONÇA, F. (Org.). Impactos socioambientais urbanos. Curitiba: Editora da UFPR, p. 185-208, 2004.

MENDONÇA, F. A. Geografia, Geografia Física e Meio Ambiente: uma reflexão a partir da problemática socioambiental urbana. ANPEGE, v.5, p.123-134, 2009.

SISTEMA DE INFORMAÇÕES GOVERNAMENTIAS DO AMAZONAS. E-SIGA. Disponível em <http://www2.e-siga.am.gov.br/portal/page/portal/esiga2009>. Acessado em 02 de mar. 2018.

TADEI, W.P, Biologia de Anofelinos Amazônicos. XVIII. Considerações sobre as espécies de Anpheles (Culicidae), transmissão e controle da malária na Amazônia. Ver. U.A. Série: Ciências da Saúde, v.2, n. 1-2, p.1-34, jan/dez /1993. 
RISCO E VULNERABILIDADE AMBIENTAL URBANA NA REGIÃO METROPOLITANA DE MANAUS

TERRAZA, W. C. M. Desenvolvimento de SIG para Análise Epidemiológica da Distribuição Espacial da Malária no Município de Manaus-Um Enfoque em Nível Local, 2005. 